\title{
A Review of the Not So Benign- Benign Childhood Epilepsy with Centrotemporal Spikes
}

Manish Parakh* and Vikash Katewa

Pediatric Medicine and Consultant Pediatric Neurologist, Dr S N Medical College, Jodhpur, India

*Corresponding author: Manish Parakh, A-314 Shastri Nagar, Opposite Hanwant School, Jodhpur, Rajasthan, 342003, India, Tel: 0091-291-2614335; E-mail: manparkh@hotmail.com

Received date: June 22, 2015; Accepted date: August 25, 2015; Published date: August 31, 2015

Copyright: $\odot 2015$ Parakh $\mathrm{M}$ et al. This is an open-access article distributed under the terms of the Creative Commons Attribution License, which permits unrestricted use, distribution, and reproduction in any medium, provided the original author and source are credited.

\begin{abstract}
Benign Childhood Epilepsy with Centrotemporal Spikes (BECTS) is one of the commonest childhood epileptic syndromes. It is also one of the most researched epilepsy syndrome and the diagnosis and management are based on standard protocol. Although in the past it was considered as a benign and self-limited entity, more and more evidences are accumulating to suggest that this condition may be associated with learning deficits in children. EEG in BECTS is diagnostic which may continue to be abnormal, years after remission from clinical seizures. From the treatment point of view, it is a debatable issue whether anticonvulsants should be used to treat BECTS? A lot of advancements in the understanding of the genetics have been observed in the last decade which may have a key role in the prevention and better management of this condition in future. The current review focuses on the newer advancements in the understanding of the clinical presentation \& pathophysiology of BECTS, its genetics and the prognosis.
\end{abstract}

Keywords: BECTS; Seizures; EEG

\section{Introduction}

The annual incidence of childhood epilepsy is estimated to be $45 / 100,000$ which is comparatively higher than in adolescence [1]. The childhood onset epilepsies can be divided into benign, intermediate, and catastrophic based on their impact on childhood development. Benign childhood focal seizures and related idiopathic epileptic syndromes affect approximately $22 \%$ of children with non-febrile seizures and constitute a significant part of day to day practice of paediatric physicians and neurologists. Benign childhood epilepsy with centrotemporal spikes, Panayiotopoulos Syndrome (PS) and the Idiopathic Childhood Occipital Epilepsy of Gastaut (ICOE-G) are the common benign epilepsy syndromes seen in childhood.

Benign childhood epilepsy with centrotemporal spikes (BECTS), also known as benign rolandic epilepsy is the best known and commonest benign focal epilepsy of childhood [2]. It is named after the rolandic area of the brain which controls movement of the face from where seizure focus is generated. This syndrome is called "benign" because most children with this syndrome outgrow the seizures by their teen years. However, lately it has been proved that in many of these children there is a high chance of having cognitive disability and learning deficits. Moreover the EEG continues to be abnormal long after the seizure remission and it is a matter of debate whether these EEG abnormalities correlate with the cognitive disability and abnormal learning in these children. Clinicians have also debated whether these children really need to be treated with anticonvulsants. There have also been significant advances in the understanding of genetics of epilepsy pathogenesis. Whether this knowledge about the genetics of BECTS will have any implications on better understanding of the clinical profile and management of these children remains to be answered. The current review focuses on recent advancements in understanding the etiopathogenesis, genetics, clinical syndrome, EEG findings and management of BECTS

\section{Synonyms of benign rolandic epilepsy}

- Benign partial epilepsy of childhood with centrotemporal spikes (BECTS)

- Benign epilepsy of childhood with rolandic spikes (BECRS)

- Silvian epilepsy

- Benign epilepsy of children with rolandic (centrotemporal) paroxysmal foci

\section{Incidence and prevalence}

Presence of spikes in EEG from rolandic area has been described since 1950. The first description of rolandic spikes in children is attributed to Gastaut, Nayrac and Beaussart [3,4]. Benign epilepsy with centrotemporal spikes (BECTS) is the most common epilepsy syndrome in children. Prevalence of benign rolandic epilepsy is around $15 \%$ in children aged $1-15$ years with non-febrile seizures and incidence is $10-20 / 100000$ children aged $0-15$ years [5-7]. Age of onset is always after 2 years and children outgrow the seizures before the age of 16 years regardless of the clinical manifestation developed during its course [8]. Most studies report a male predominance with a male to female ratio of approximately $3: 2$ [9].

\section{Clinical manifestation and seizure semiology}

Seizures mostly occur during NREM sleep, mainly at sleep onset or just before awakening although children may experience seizures during awake stage also. Seizure semiology begins with an aura of unilateral tongue or perioral paresthesia. The cardinal feature of rolandic epilepsy includes focal seizures in form of unilateral facial sensory-motor symptoms (30\% patients), hypersalivation (30\%), speech arrest (40\%) and oro-pharyngo-laryngeal symptoms (OPLS) 
(53\%) $[2,10]$. Onset of hemifacial sensory-motor seizures usually occurs from lower lip that may spread to ipsilateral hand. Sensory manifestations consist of numbness around the corner of mouth. Motor symptoms manifest in form of clonic contractions which may be associated with ipsilateral tonic deviation of angle of mouth. OPLS symptoms are the most characteristic of all other ictal symptoms of rolandic epilepsy. These symptoms consist of unilateral sensory and motor manifestations inside the mouth, teeth, inner cheek, gums, tongue and pharyngo-laryngeal regions. Sensory symptoms are usually diffuse on one side which usually manifest in form of unilateral numbness and more commonly paraesthesias (tingling, prickling, freezing and their variations). Rarely sensory symptoms may be highly localised to even one tooth. Motor OPL symptoms presents with strange sounds like gurgling, grunting, death rattle or guttural sounds. Most a time these sounds are what let parents know their child is having a seizure at night. Child may experience speech arrest and he may be actually anarthric, where the child is perfectly able to understand what is being said, but unable to utter a single intelligible word and tries to communicate with gestures. There is no impairment of cortical language mechanism The speech arrest is due to anarthia attributed to loss of the power and coordination of the musculature responsible for the articulation of words which also explain why speech arrest is equally common in left or right sided rolandic seizures. Hypersalivation is one of the most characteristic ictal symptoms of rolandic epilepsy and probably occurs in as many as one third of cases. It may be associated with OPL symptoms as well as may be associated with pure hemifacial seizures. A seizure which begins on one side of face may spread to an arm or leg or may become secondarily generalized. Progression to hemiconvulsions or generalized tonicclonic seizures (GTCS) occurs in around half of children and hemiconvulsions may be followed by postictal Todd's hemiparesis [11]. Duration of seizures is usually brief, lasting for 1-2 minutes. If the seizure becomes generalized, the onset is usually not witnessed. Daytime seizures are almost exclusively simple partial involving the face and tongue. The role of sleep in facilitating the secondary generalization is fascinating and unexplained. Consciousness is fully retained in more than half (58\%) of the patients and are able to describe the events after the end of the event.

\section{EEG manifestations}

EEG is the corner stone for the diagnosis of rolandic epilepsy. Centrotemporal spikes (CTS) are the hallmark of the syndrome of BCECTS. They are characterised by their morphology, amplitude and duration, location and field distribution, frequency and pattern of occurrence, reactivity to external stimuli and the sleep-wake cycle, as well as age-dependence and evolution. It is important to perform a wake-sleep EEG because the spike-wave discharges are activated as the patient enters the sleep phase of the study. Although called centrotemporal spikes, these are mainly high amplitude sharp and slow wave complexes localised in the $\mathrm{C} 3 / \mathrm{C} 4$ (high central) in $30 \%$ of patients and C5/C6 (low central region, midway between central and temporal) electrodes in $70 \%$. Centrotemporal spikes have a typical field of distribution forming a transverse dipole with a surface negativity seen in the mid temporal central region and a surface positivity seen in superior frontal region which has been confirmed in magnetoencephalographic studies $[12,13]$. The main spike (sharp wave) component is diphasic with a maximum negative surface, negative, rounded peak that is preceded by a small positive wave and followed by a prominent positive wave with an amplitude frequency up to $50 \%$ that of preceding negative sharp wave. The amplitude of the main spike (or sharp wave) component often exceeds $200 \mu \mathrm{V}$, though it may be much smaller or much higher. Spike focus is unilateral in about 60 percent of patients and bilateral in 40 percent, with bilateral discharge occurring synchronously or asynchronously [14]. When unilateral, the distribution between both hemispheres is almost equal [15]. The spike foci tend to shift from side to side in patients with bilateral focus. The spike focus may be ipsi- or contra lateral to the symptomatogenic side. Discharges often occur in clusters, with a frequency of 1.5 to $3 \mathrm{HZ}$. Spikes increase during stages I-IV of sleep by a factor of 2-5 times without disturbing the sleep organisation. In serial EEG, spikes may appear right or left, infrequent or abundant, small or giant, alone or with functional spikes in other locations. CTS are not solely associated with BECTS. CTS may be found in $2-3 \%$ of normal school-age children, of whom less than $10 \%$ develop rolandic epilepsy [16,17]. Age-dependent CTS frequently occur in a variety of organic brain diseases with or without seizures, such as cerebral tumours, Rett syndrome, fragile $\mathrm{X}$ syndrome and focal cortical dysplasia. Furthermore, CTS may incidentally be found in nonepileptic children with various symptoms, such as headache speech, behavioural and learning difficulties. CTS are also observed in more complex epilepsy syndrome such as Landau-Kleffner syndrome (LKS), epileptic encephalopathy with continuous spike-and-wave during sleep (CSWS), and atypical benign partial epilepsy [18]. CTS are also observed in 10-28\% of children with autistic spectrum disorder as well as in $6 \%$ children with attention deficit disorder $[19,20]$. CTS may be activated by drowsiness, however unlike absence seizures hyperventilation have no effect on generation of CTS [21]. The voluntary manoeuvre of protrusion of tongue may inhibit centrotemporal spikes and terminate seizures [22]. Neuroimaging is usually not indicated in most patients but may be indicated in those with atypical features such as persistent seizures and long duration of seizures. However, Lundberg et al. has described hippocampal asymmetries and white matter abnormalities in one third patients with BECTS examined with MRI [23]. In a study to evaluate regional cerebral metabolism in patients with BECTS using FDG-PET, no metabolic changes associated with interictal spiking were found [24]. This study suggested that this technique could be helpful for differentiation between idiopathic and symptomatic cases of partial epilepsy in children.

\section{Genetics}

BECTS has been studied extensively from a genetic point of view. Until recently it was assumed that hereditary features play a key role in BECTS [25]. Bray and Wiser examined EEG abnormalities and seizures in the siblings of children with seizures and temporocentral spikes or sharp waves and postulated that an autosomal dominant inheritance pattern with age-dependent penetrance refers to the EEG trait and not to the clinical syndrome of rolandic epilepsy [26]. Failure to find a convincing genetic basis for BECTS in a recent study of 18 monozygotic twins has suggested that heredity is multifactorial $[27,28]$. These observations led to the recent reclassification of BECTS as an epilepsy syndrome of unknown etiology rather than the older system in which it was referred to as idiopathic [29].

Several attempts have been made to identify the gene predisposing to BECTS. Neubauer et al. recently evaluated linkage of BECTS to chromosomal regions known to contain genes coding for subunits of the neuronal nicotinic acetylcholine receptor [30]. In this study evidence for linkage to chromosome $15 \mathrm{q} 14$ was obtained with a maximal LOD score of 3.56 under an autosomal recessive mode of 
inheritance but no mutation was identified. Similarly in other recent studies despite promising logarithm of odds (LOD) scores, no genetic mutations have been identified [31,32]. Recent studies in some families has shown an overlap between epileptic encephalopathy with CSWS, atypical benign partial epilepsy, and BECTS which has led to the concept of a spectrum of epilepsy-aphasia disorders with BECTS at the lower end, the broad less well-defined group of epilepsy-aphasia children in the middle, and classical LKS and the syndrome of CSWS at the extreme end [30,33-35]. This overlap suggests an additional genetic as well as environmental factors which determine whether the spectrum of disease will manifest as BECTS or as epileptic- aphasia spectrum disorder.

\section{Treatment}

Whether to initiate antiepileptic drugs (AED) or not, in children with BECTS is a matter of debate. In the past BECTS was considered to be a benign disorder with no long term neurological consequences. But recent studies in past decade have found that patients with BECTS have a variety of cognitive disturbances including language impairment, memory dysfunction, and auditory processing difficulties. These observations have prompted us to reconsider the old theory of not to treat these children with AED. Most AED are however considered to be effective [10].Most common AEDs used to treat this disease include carbamazepine, oxcarbazepine and levetiracetam, gabapentin and lamotrigine [36-38].Recent studies have indicated that children with BECTS have specific deficit in visual, verbal and linguistic domain not only during active stage of disease but these may persist even after remission [39-40]. The treatment should be considered individually for each child. Whether to treat or not should be based on risk - benefit assessment. The benefit associated with treatment may be in form of control of seizures and effect on cognitive consequences. Children who have frequent seizures, day time seizures or who have troubled learning should be treated with antiepileptic drugs (AED). The 2006 ILAE treatment guidelines found that no AED had level A or level B efficacy and effectiveness evidence as initial monotherapy' in rolandic epilepsy [41]. Recently, sulthiame (available only in a few countries) has been revived as an excellent drug for the treatment of rolandic epilepsy with statistically significant evidence in controlling seizures and EEG normalization but this may be associated with cognitive abnormalities in form of significant decline in memory and reduction in attention and mathematics ability $[42,43]$. Though considered to be benign epilepsy, some patients suffer from negative cognitive consequences. So for this reason an individualized riskbenefit assessment is required to make an informed decision as to the appropriate therapy. Based on currently available data, most patients will not require anticonvulsant therapy except the patients who develops daytime seizures or very frequent nocturnal seizure as well as patients who evolve to ESES or who develop status epilepticus should be treated [44].

\section{Evolution and Prognosis}

Prognosis of BECTS is excellent. By the mid teenage children outgrow of the disease in $100 \%$ cases [45]. Persistence of epilepsy during adulthood after benign rolandic epilepsy in childhood is found to be a different syndrome [45]. During the course of illness 10-20\% children have just single seizures while $10-20 \%$ children develop frequent seizures but these also remit with age. Children with rolandic seizures may develop usually mild and reversible linguistic, cognitive and behavioural abnormalities during the active phase of the disease
[46]. These abnormalities are expected due to the superimposition of the cortical areas for language with those of the RS, which concentrate in the lower part of the rolandic area and in the sylvian region, with an eventual extension into the temporal cortex and adjacent parietal region [47,48]. Benign rolandic epilepsy disrupts development in childhood only if it interferes with the child's chances for normal friendships. Interference in child's normal social activities may affect his/her sense of self-worth.

\section{Conclusion}

With the aforementioned review it is amply clear that Benign Epilepsy with Centrotemporal spikes is not so benign and may be associated with significant learning disabilities and cognitive abnormalities. Few researchers have teased apart the EEG abnormalities in BECTS and have also found correlation of various interictal epileptiform discharges with specific learning deficits, but more research is required to prove or disprove this observation. There have been advancements in understanding the genetics of BECTS, however at this point in time cannot be translated into prevention and better management. It also seems prudent to not start an anticonvulsant for routine management of BECTS as it does not have any clear benefit in the overall management of these patients and may add to the pre-existing cognitive impairment due to BECTS.

\section{References}

1. Camfield CS, Camfield PR, Gordon K, Wirrell E, Dooley JM (1996) Incidence of epilepsy in childhood and adolescence: a population-based study in Nova Scotia from 1977 to 1985. Epilepsia 37: 19-23.

2. Fejerman N (2008) Benign childhood epilepsy with centrotemporal spikes. In: Engel J Jr, Pedley TA, editors. Philadelphia: Lippincott Williams and Wilkins, A Wolters Kluwer Business 2369-2377.

3. Gastaut Y (1952) Un élément déroutant de la séméiologie électroencéphalographique: les pointes prérolandiques sans signification focale. Rev Neurol 87: 488-490.

4. Nayrac P, Beaussart M (1958) Pre-rolandic spike-waves: a very peculiar EEG reading; electroclinical study of 21 cases. Rev Neurol (Paris) 99: 201-206.

5. Larsson K, Eeg-Olofsson O (2006) A population based study of epilepsy in children from a Swedish county. Eur J Paediatr Neurol 10: 107-113.

6. Heijbel J, Blom S, Bergfors PG (1975) Benign epilepsy of children with centrotemporal EEG foci. A study of incidence rate in outpatient care. Epilepsia 16: 657-664.

7. Astradsson A, Olafsson E, Ludvigsson P, Björgvinsson H, Hauser WA (1998) Rolandic epilepsy: an incidence study in Iceland. Epilepsia 39: 884-886.

8. Loiseau P, Duché B, Cordova S, Dartigues JF, Cohadon S (1988) Prognosis of benign childhood epilepsy with centrotemporal spikes: a follow-up study of 168 patients. Epilepsia 29: 229-235.

9. Ma CK, Chan KY (2003) Benign childhood epilepsy with centrotemporal spikes: a study of 50 Chinese children. Brain Dev 25: 390-395.

10. Wirrell E, Camfield CS, Camfield PR (2006). Idiopathic and bening partial epilepsies of childhood. In: Wyllie E, Gupta A, Lachhwani D, editors. The treatment of epilepsy. 4th edn. Philadelphia: Lippincott Williams and Wilkins 373-389.

11. Doose H, Petersen B, Neubauer BA (2002) Occipital sharp waves in idiopathic partial epilepsies--clinical and genetic aspects. Epilepsy Res 48: 121-130.

12. Luders H, Lesser RP, Dinner DS, Morris HH III (1987) Benign focal epilepsy of childhood. In : Luders H, Lesser RP(eds) Electroclinical syndromes. Berlin: Springer-Verlag 303-346.

13. Kamada K, Moller M, Saguer M, Kassubek J, Kaltenhäuser M, et al. (1998) Localization analysis of neuronal activities in benign rolandic 
epilepsy using magneto encephalography. Journal of the Neurological Sciences 154: 164-172.

14. Holmes GL(1993) Benign focal epilepsies of childhood. Epilepsia 34 Suppl 3: S49-61.

15. Loddenkemper T, Burgess RC, Syed T, Pestana EM (2007) Lateralization of interictal EEG findings. J Clin Neurophysiol 24: 379-385.

16. Cavazzuti GB, Cappella L, Nalin A (1980) Longitudinal study of epileptiform EEG patterns in normal children. Epilepsia 21: 43-55.

17. Okubo Y, Matsuura M, Asai T, Asai K, Kato M, et al. (1994) Epileptiform EEG discharges in healthy children: prevalence, emotional and behavioral correlates, and genetic influences. Epilepsia 35: 832-841.

18. Doose H, Brigger-Heuer B, Neubauer B (1997) Children with focal sharp waves: clinical and genetic aspects. Epilepsia 38: 788-796.

19. Chez MG, Chang M, Krasne V, Coughlan C, Kominsky M, et al. (2006) Frequency of epileptiform EEG abnormalities in a sequential screening of autistic patients with no known clinical epilepsy from 1996 to 2005. Epilepsy Behav 8: 267-271.

20. Holtmann M, Becker K, Kentner-Figura B, Schmidt MH (2003) Increased frequency of rolandic spikes in ADHD children. Epilepsia 44: 1241-1244.

21. Clemens B, Majoros E (1987) Sleep studies in benign epilepsy of childhood with rolandic spikes. II. Analysis of discharge frequency and its relation to sleep dynamics. Epilepsia 28: 24-27.

22. Veggiotti P, Beccaria F, Gatti A, Papalia G, Resi C, et al. (1999) Can protrusion of the tongue stop seizures in Rolandic epilepsy? Epileptic Disord 1: 217-220.

23. Lundberg S, Eeg-Olofsson O, Raininko R, Eeg-Olofsson KE (1999) Hippocampal asymmetries and white matter abnormalities on MRI in benign childhood epilepsy with centrotemporal spikes. Epilepsia 40: 1808-1815.

24. Van Bogaert P, Wikler D, Damhaut P, Szliwowski HB, Goldman S (1998) Cerebral glucose metabolism and centrotemporal spikes. Epilepsy Res 29: 123-127.

25. Commission on Classification and Terminology of the International League Against Epilepsy (1989). Proposal for revised classification of epilepsies and epileptic syndromes. Epilepsia 30: 389-399.

26. Bray PF, Wiser WC (1965) Hereditary characteristics of familial temporal-central focal epilepsy. Pediatrics 36: 207-211.

27. Vadlamudi L, Harvey AS, Connellan MM, Milne RL, Hopper JL, et al. (2004) Is benign rolandic epilepsy genetically determined? Ann Neurol 56: 129-132.

28. Vadlamudi L, Kjeldsen MJ, Corey LA, Solaas MH, Friis ML, et al. (2006) Analyzing the etiology of benign rolandic epilepsy: a multicenter twin collaboration. Epilepsia 47: 550-555.

29. Berg AT, Berkovic SF, Brodie MJ, Buchhalter J, Cross JH, et al. (2010) Revised terminology and concepts for organization of seizures and epilepsies: report of the ILAE Commission on Classification and Terminology, 2005-2009. Epilepsia 51: 676-685.

30. Neubauer BA, Fiedler B, Himmelein B, Kämpfer F, Lässker U, et al. (1998) Centrotemporal spikes in families with rolandic epilepsy: linkage to chromosome 15q14. Neurology 51: 1608-1612.

31. Strug LJ, Clarke T, Chiang T, Chien M, Baskurt Z, et al. (2009) Centrotemporal sharp wave EEG trait in rolandic epilepsy maps to Elongator Protein Complex 4 (ELP4). Eur J Hum Genet 17: 1171-1181.

32. Pal DK, Li W, Clarke T, Lieberman P, Strug LJ (2010) Pleiotropic effects of the 11p13 locus on developmental verbal dyspraxia and EEG centrotemporal sharp waves. Genes Brain Behav 9: 1004-1012.
33. De Tiège X, Goldman S, Verheulpen D, Aeby A, Poznanski N, et al. (2006) Coexistence of idiopathic rolandic epilepsy and CSWS in two families. Epilepsia 47: 1723-1727.

34. Hirsch E, Marescaux C, Maquet P, Metz-Lutz MN, Kiesmann M, et al. (1990) Landau-Kleffner syndrome: a clinical and EEG study of five cases. Epilepsia 31: 756-767.

35. Deonna TW, Roulet E, Fontan D, Marcoz JP (1993) Speech and oromotor deficits of epilpetic origin in benign partial epilepsy of childhood with rolandic spikes (BPERS). Relationship to the acquired aphasia-epilepsy syndrome. Neuropediatrics 24: 83-87.

36. Verrotti A, Coppola G, Manco R, Ciambra G, Iannetti P, et al. (2007) Levetiracetam monotherapy for children and adolescents with benign rolandic seizures. Seizure 16: 271-275.

37. Marson AG, Al-Kharusi AM, Alwaidh M, Appleton R, Baker GA, et al. (2007) SAMA Study group. The SANDAD study of effectiveness of carbamazepine, gabapentin, lamotrigine, oxcarbazepine, or topiramate for treatment of partial epilepsy: an unblended randomized control trial. Lancet 369: 1000-1015.

38. Coppola G, Franzoni E, Verrotti A, Garone C, Sarajlija J, et al. (2007) Levetiracetam or oxcarbazepine as monotherapy in newly diagnosed benign epilepsy of childhood with centrotemporal spikes (BECTS): an open-label, parallel group trial. Brain Dev 29: 281-284.

39. Piccinelli P, Borgatti R, Aldini A, Bindelli D, Ferri M, et al. (2008) Academic performance in children with rolandic epilepsy. Dev Med Child Neurol 50: 353-356.

40. Monjauze C, Tuller L, Hommet C, Barthez MA, Khomsi A (2005) Language in benign childhood epilepsy with centro-temporal spikes abbreviated form: rolandic epilepsy and language. Brain Lang 92: 300-308.

41. Glauser T, Ben-Menachem E, Bourgeois B, Cnaan A, Chadwick D, et al. (2006) ILAE treatment guidelines: evidence-based analysis of antiepileptic drug efficacy and effectiveness as initial monotherapy for epileptic seizures and syndromes. Epilepsia 47: 1094-120.

42. Bast T, Völp A, Wolf C, Rating D; Sulthiame Study Group (2003) The influence of sulthiame on EEG in children with benign childhood epilepsy with centrotemporal spikes (BECTS). Epilepsia 44: 215-220.

43. Wirrell E, Sherman EM, Vanmastrigt R, Hamiwka L (2008) Deterioration in cognitive function in children with benign epilepsy of childhood with central temporal spikes treated with sulthiame. J Child Neurol 23: 14-21.

44. Shields WD, Snead OC 3rd (2009) Benign epilepsy with centrotemporal spikes. Epilepsia 50 Suppl 8: 10-15.

45. Bouma PA, Bovenkerk AC, Westendorp RG, Brouwer OF (1997) The course of benign partial epilepsy of childhood with centrotemporal spikes: a meta-analysis. Neurology 48: 430-437.

46. Giordani B, Caveney AF, Laughrin D, Huffman JL, Berent S, et al. (2006) Cognition and behavior in children with benign epilepsy with centrotemporal spikes (BECTS). Epilepsy Res 70: 89-94.

47. Piccirilli M, D'Alessandro P, Tiacci C, Ferroni A (1988) Language lateralization in children with benign partial epilepsy. Epilepsia 29: 19-25.

48. Wolff M, Weiskopf N, Serra E, Preissl H, Birbaumer N, et al. (2005) Benign partial epilepsy in childhood: Selective cognitive deficits are related to the location of focal spikes determined by combined EEG/ MEG. Epilepsia 46: 1661-1667. 